\title{
CARACTERIZAÇÃO GEAMBIENTAL DO DISTRITO DE HUMILDES - FEIRA DE SANTANA-BA
}

\author{
Jardel Sodré Farias ${ }^{1}$; Gracinete Souza Bastos²; Juliele Nascimento Jeusus ${ }^{3}$ e Nadine de \\ Jesus $\operatorname{Santos}^{4}$ \\ 1. Bolsista PIBIC/FAPESB, Graduando em En genh aria Civil, Universidade Estadual de Feira de Santana, e-mail: \\ jardel.sfarias@gmail.com \\ 2. Orientadora, Departamento de Exatas, Universidade Estadual de Feira de Santana, e-mail: graciesouza@ gmail.com \\ 3. Particip ante do projeto, Departamento de Tecnologia, Universidade Estadual de Feira de Santana, e-mail: \\ njjuliele@gmail.com \\ 4. Participante do projeto, Departamento de Tecnologia, Universidade Estadual de Feira de Santana, e-mail: \\ nadinesanttos@gmail.com
}

PALAVRAS-CHAVE: Mapeamento Geotécnico; Feira de Santana; Humildes.

\section{INTRODUÇÃO}

Após realizar um zoneamento geotécnico de Feira de Santana, Bastos (1996) afirma que o município é mais um dentre as várias cidades médias brasileiras que sofrem problemas de ocupação desordenada, causada pela falta de planejamento urbano. $O$ aumento populacional rápido gerou uma expansão sem controle, desrespeitando as características do meio físico, que resultou em vários problemas como a falta de saneamento básico, a poluição de águas superficiais e subterrâneas e, além disso, a contaminação do solo e aparecimento de erosões.

Por isso, estudos geológicos e ambientais em áreas pouco expandidas podem ajudar a prevenir a degradação ambiental e contribuir para o planejamento urbano. Humildes está localizado no lado leste de Feira de Santana e é o distrito que apresenta o maior número de habitantes residindo em área urbana (5.660), o que dá um percentual de 44,2\% de sua população (Censo Demográfico - 2000), podendo-se atribuir isso ao de desenvolvimento de atividades comerciais e industriais na sede do distrito. Isso faz com que o distrito tenha uma representatividade econômica notável, embora esse aumento gradativo populacional e industrial de Humildes cause prejuízos ao meio ambiente e a exploração exagerada dos recursos naturais.

De acordo com Freitas \& Campanha (2007, apud Franco et al. 2010), a cartografia geotécnica vem se tornando importante instrumento técnico da gestão ambiental, pois fornece, através da representação do conhecimento geológico, as diretrizes para que as atividades humanas minimizem o comprometimento da qualidade ambiental e os seus impactos.

Desta forma, este trabalho tem como objetivo caracterizar o meio físico do distrito de Humildes quanto às propriedades dos materiais constituintes (rochas, material incosolidado e águas), em relação aos processos geodinâmicos naturais e/ou induzidos e às modificações desses materiais diante das intervenções humanas (uso e ocupação do solo). Assim, as informações da cartografia geotécnica atendem as necessidades da gestão ambiental em seus vários níveis, o que é importante para o distrito de Humildes.

\section{MATERIAL E MÉTODOS}

Na primeira etapa do estudo foi realizada uma revisão bibliográfica e levantamento de informações pré-existentes sobre a área de pesquisa, através de consulta a livros, artigos, relatórios anteriores, mapas e monografias que serviram de embasamento teórico para o desenvolvimento do trabalho e apresentaram informações sobre a localidade.

Para a elaboração de mapas temáticos, armazenamento e integração de dados, utilizouse o Sistema para Processamento de Informações Georeferrenciadas (SPRING) 5.3, um 
software de domínio público que pode ser adquirido pela internet. Durante a pesquisa, utilizou-se o mapa do município de Feira de Santana, fornecido pelo IBGE; a imagem produzida pela EMBRAPA, a qual apresenta o relevo de Feira de Santana, obtida através do site <http://www.relevobr.cnpm.embrapa.br/ba/hth0/ba34_72.htm>.

Para extrair a hidrografia do local, utilizou-se também o material da Superintendência de Estudos Econômicos e Sociais da Bahia (SEI), intitulado Base Cartográfica Digital Estado da Bahia (Mapeamento Topográfico Sistemático 1:100.000); para o trabalho de campo foi utilizado o GPS, trena e uma máquina fotográfica.

As atividades de campo foram realizadas entre dezembro de 2015 e Junho de 2016, nas quais se pode documentar e identificar in loco a morfologia, o material inconsolidado, a vegetação, a drenagem, as rochas, as formas de uso do terreno e os efeitos da ação do homem no ambiente (esgotos, lixo, desmatamento, etc.). Para nortear o reconhecimento de campo foi projetado anteriormente um roteiro, o qual continha basicamente o trajeto que seria percorrido. Para isso, fez-se o uso do software livre Wikimapia e com a ferramenta "Distância" pode-se traçar a rota pelas estradas do distrito. Logo, conhecendo-se as distâncias entre pontos desejados e as coordenadas dos mesmos, foi possível se localizar e seguir o roteiro durante todo o traje to. Visto que o trabalho em questão não fez ensaios em laboratório para a caracterização do material inconsolidado, realizou-se apenas identificação tátil-visual no próprio campo, seguindo as especificações de Pinto (2000)

\section{RESULTADOS E/OU DISCUSSÃO}

A região leste do município de Feira de Santana tem como característica principal uma camada de material arenoso que cobre grande parte da superfície. No entanto, este material por muitas vezes desaparece, ressurgindo apenas em pequenas manchas localizadas (BASTOS, 1996). Esses aspectos puderam ser comprovados e reconhecidos no trabalho de campo, visto que foram encontrados diversos pontos com cobertura arenosa, sendo alguns deles bolsões de areia nos quais, provavelmente, ocorre extração da mesma. Essa extração de areia sem o devido controle e fiscalização pode causar problemas ambientais, como assoreamento de rios e erosão do solo, o que já pode ser notado durante as visitas de campo.

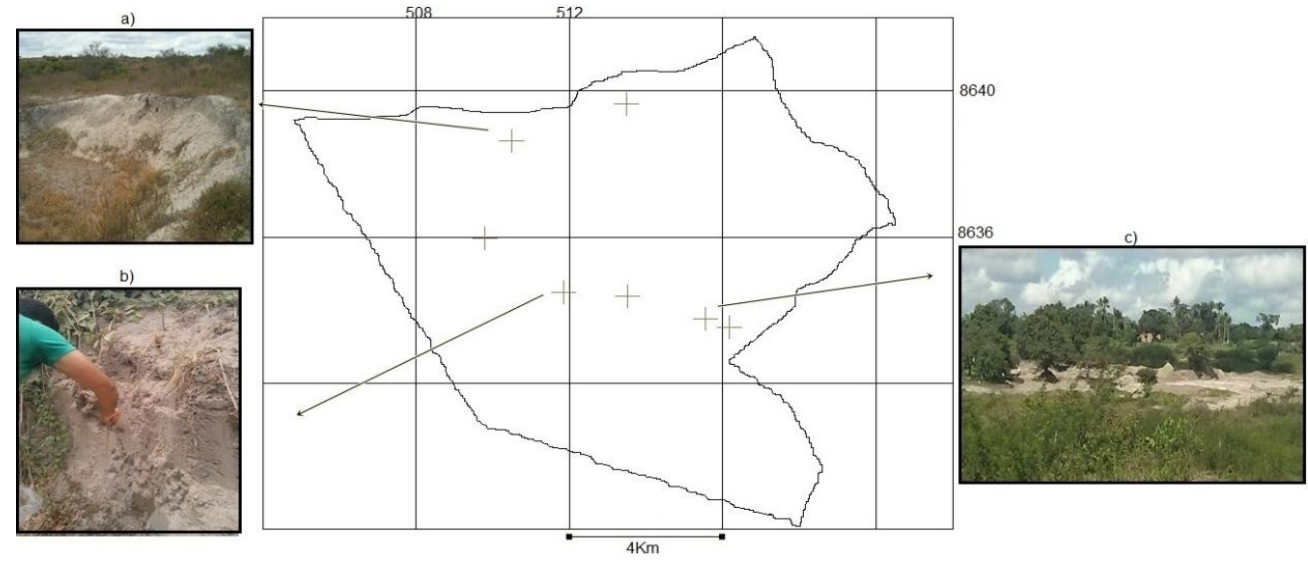

Figura 1: Pontos de amostra de materiais inconsolidados. a) Bolsão de areia no povoado de Terra Dura; b) Ponto de coleta de solo arenoso; c) Bolsão de areia no povoado Bom Viver

Através do reconhecimento de campo foi constatada a presença de erosão. Em sua maioria, as erosões observadas foram causadas pela ação das águas pluviais, porém, notou-se que algumas delas foram ocasionadas por ações antrópicas, extração de areia, como citado anteriormente.

Bastos (1996) conclui que as características geológicas, quanto a sua distribuição na área do município, divide-se basicamente da seguinte forma: do lado leste e oeste extrato rochoso cristalino, enquanto na faixa central está localizado o pacote sedimentar. Dessa 
forma, o distrito de Humildes, por está localizado do lado leste, apresenta o extrato rochoso cristalino. Também, foi possível observar em campo depósito sedimentar de Formação Barreiras, o qual segundo Bastos (1996) é constituído normalmente de concentrações ferruginosas com matriz argilosa, de cor variando entre amarelo e vermelho, o que pode ser cons tatado com a presença de lateritas no solo.

Analisando a curvas de níveis extraídas da imagem fornecida pela EMBRAPA, percebeu-se que altitude do local sofre pouca variação, oscilando de $150 \mathrm{~m}$ até $240 \mathrm{~m}$, o que está de acordo com Bastos (1996), a qual afirma que o relevo do município de Feira de Santana é em sua essência plano. Constatou-se isso em campo, no qual foram identificadas poucas elevações, caracterizando-se um relevo levemente ondulado.

A figura 2 apresenta a topografia da região com curvas de níveis equidistando em 20m. Além disso, pode-se perceber através da gradação em níveis de cinza da imagem que: o cinza claro representa regiões mais altas e o cinza escuro regiões mais baixas.

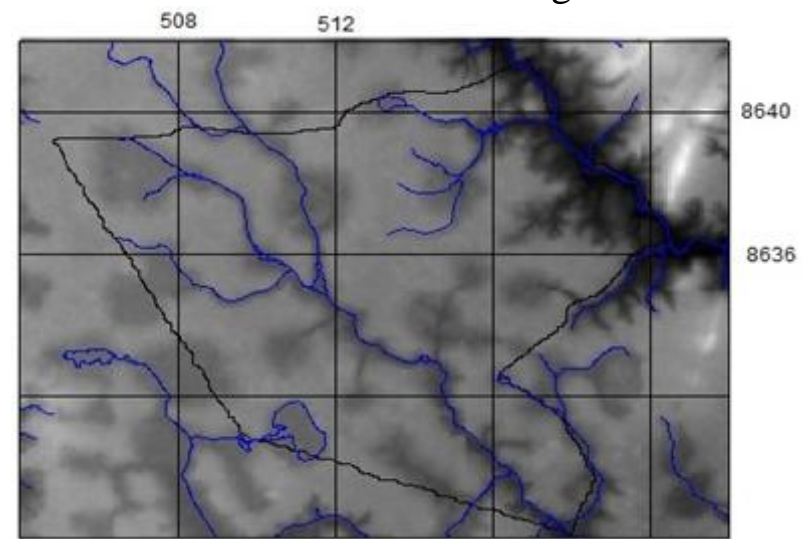

Figura 2 : Imagem importada do SPRING 5.3; Em preto o limite distrital e em azul os rios.

A principal drenagem do distrito de Humildes é o Rio Subaé, no entanto, também está presente na extremidade norte parcelas do Rio Pojuca. Segundo Bastos (1996), o Rio Pojuca localiza-se no lado leste da cidade, de leito estreito, escoando sobre rochas cristalinas. Enquanto o Rio Subaé nasce no próprio município, ao sul, numa lagoa que recebe o mesmo nome. Segundo (BORGES et al 2013) edificações irregulares, ausência de esgotamento sanitário e mata ciliar, em alguns trechos do Rio Subaé em Feira de Santana, refletiram no assoreamento da calha e redução de vazão do rio, como foi possível verificar durante o reconhecimento de campo, no qual se verificou que a parcela do Rio que se encontra dentro dos limites da área estudada está completamente assoreada, restando apenas pequenas lagoas em alguns trechos.

De acordo com Bastos (1996), a região estudada está dentro da área da Floresta Estacional Decidual e Semidecidual, caracterizada com clima de duas estações definidas, uma mais chuvosa e outra mais seca. No entanto, atualmente a vegetação original dá lugar à agricultura, com culturas diversas e rotativas, destacando a cultura de hortaliças (bastante presente no distrito) e a pecuária. O distrito apresenta cerca de $50 \%$ da sua população residindo em área urbana, onde se encontra escolas, postos de saúde, cartório e postos policiais. 


\section{CONCLUSÕES}

Após os estudos realizados, no que se refere ao material incosolidado, o distrito apresenta uma camada de material arenoso, embora também tenha presença de silte e argila. Já o relevo é basicamente plano, apresentando algumas pequenas ondulações. Com relação à hidrografia, todos os rios da localidade são intermitentes, podendo-se perceber uma contradição entre os mapas dos rios e análises de campo. Pois em campo foram encontradas apenas pequenas lagoas, rios completamente assoreados e sem uma mata ciliar necessária, resultado de um desenvolvimento sem planejamento e predatório como, por exemplo, a extração de areia encontrada em diversos pontos do distrito. Essas atividades extrativistas, quando realizadas sem o devido cuidado e fiscalização, podem acarretar em desmatamento, assoreamento dos rios e também erosões.

Planejamento urbano, desenvolvimento ecológico e preservação ambiental são características almejadas por diversos países, cidades e também distritos, que são áreas em desenvolvimento, fazendo-se necessário o conhecimento obtido a partir do mapeamento geotécnico e geoambiental. Logo, percebe-se a importância da caracterização realizada no distrito, a qual servirá como uma ferramenta para o planejamento territorial, respeitando o meio ambiente e proporcionando uma ocupação racional e adequada.

\section{REFERÊNCIAS}

BASTOS, G. (1996). Estudo com Sistema de Informação Geográfica para o Mapeamento Geotécnico do Município de Feira de Santana-BA. Dissertação de Mestrado, Publicação GDM-035A/96, Departamento de Engenharia Civil, Universidade de Brasília, Brasília-DF. BORGES, L, F, M, B. ARAUJO, N, S. SANTOS, P, S. NASCIMENTO, D, M, C. Estudo De Uso E Ocupação Da Terra Da Bacia Hidrográfica Do Rio Subaé - Estado Da Bahia.

EMBRAPA, Embrapa Monitoramento por Satélite. Disponível em: < http://www.relevobr.cnpm.embrapa.br/ba/hth0/ba34_72.htm>. Acesso em 01 de agosto de 2015. IBGE (Instituto Brasileiro de Geografia e Estatística). Dados Censitários, 2000. Disponível em: <http $/ /$ www.sidra.ibge.gov.br/bda/tabela/protabl.asp? $\mathrm{z}=\mathrm{t} \& \mathrm{o}=3 \& \mathrm{i}=\mathrm{P}>$. Acesso em: 01 de agosto de 2015.

FREITAS, C, G, L. de; CAMPANHA, V. A. Carta geotécnica e ambiental aplicada em planos diretores municipais. In: Simpósio Brasileiro De Cartografia Geotécnica E Geoambiental, 6, Uberlândia. Anais... Uberlândia: ABGE, 2007

INDA, H.A.V.; BARBOSA, J.F. Mapa Geoló gico do Estado da Bahia. Salvador: Secretaria das Minas e Energia, 1978. 1 mapa: color., $120 \mathrm{~cm} \mathrm{x} \mathrm{106cm.} \mathrm{Escala} \mathrm{1:} 1000.000$.

MELLO, Filipe Ramos; CHAVES, Joselisa Maria. Mapeamento Do Uso E Ocupação Do Solo Urbano De Feira De Santana-Ba, Utilizando Imagens De Média Resolução Das Plataformas Cbers 2 E Landsat 7. I Simpósio Nacional de Recursos Tecnológicos Aplicados à Cartografia e XVIII Semana de Geografia. ISSN 2175-5965, p. 207-218. Maringá, 21 a 25 de setembro de 2009.

PINTO, C.S. Curso Básico de Mecânica dos Solos, Oficina de textos, 2000.

PROJETO RADAMBRASIL. Mapa de Vegetação, Folha SD.24. Ministério das Minas e Energia:1981. 1 mapa color. Escala 1:1000.000.

ZUQUETTE, L.V. (1987). Análise Crítica da Cartografia Geotécnica e Proposta Metodológica para as Condições Brasileiras. Tese de Doutorado, USP/EESC, São Carlos, SP. 